\title{
EN TORNO A LA ICONOGRAFÍA DEL TRIUNFO DE SAN GREGORIO DE JUAN DE ROELAS
}

Son muy pocos datos y las referencias antiguas que tenemos sobre el llamado Triunfo de San Gregorio (fig. 1) que nos pueda ayudar a entender su iconografía. Las únicas fuentes directas sobre su encargo son tres recibos firmado por Juan de Roelas, por el que recibía distintas cantidades de dinero y fechados entre julio y noviembre de 1608, y en los que sólo en el primero de ellos se hace referencia al "cuadro de San gregorio qe boy pintando". La descripción más interesante la aporta un inventario, ya bastante tardío, en la que el pintor Juan de Espinal interviene como

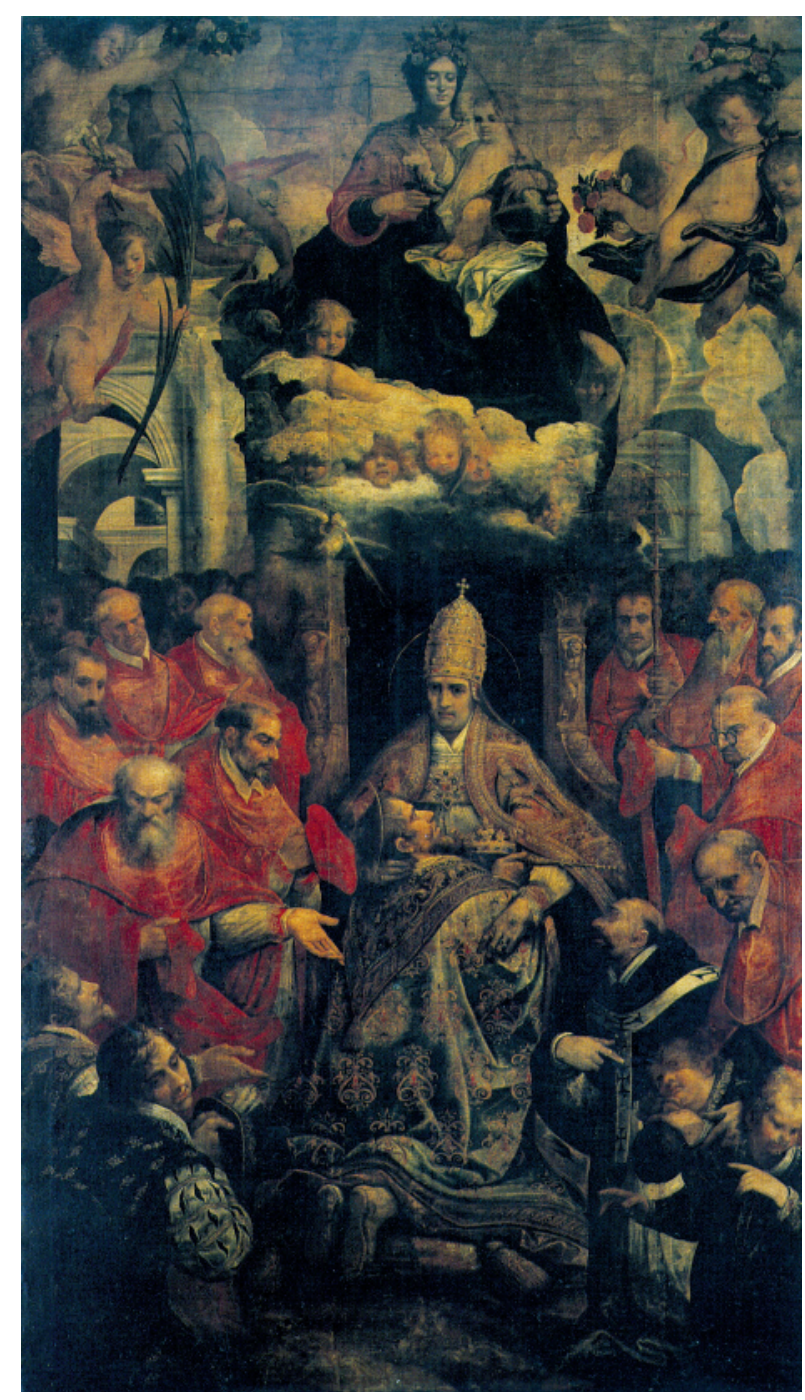

Fig. 1. Juan de Roelas. El Triunfo de San Gregorio. 1608. Ushaw Collage. Dirham (Inglaterra).

1 Angulo, Diego, "El Cuadro de San Gregorio de Roelas". Boletín del Seminario de Estudios de Arte y Arqueología. Valladolid, 1935-36. p. 57. 
tasador de los bienes del colegio. En este inventario de 1767 se describe esta pintura, que ocupaba el altar mayor de la iglesia, como el "Señor San Gregorio con la Virgen y acompañamiento de Ángeles, $y$ distintos cardenales", y que Espinal atribuía al "clérigo Rodelas". Se completaba este altar con un apostolado de medio cuerpo que rodeaba a la pintura principal, copias de grabados de Hendrik Goltzius, y en el ático otras tres pinturas, que Espinal también atribuía a Roelas, que se correspondían con un Salvator Mundi de medio cuerpo flanqueado por unas alegorías de la $\mathrm{Fe}$ y de la Esperanza ${ }^{2}$.

La fundación del Colegio de San Gregorio tuvo lugar en el año 1592 por el impulso del jesuita inglés Robert Parsons, contando también con la protección del rey Felipe $\mathrm{II}^{3}$. Robert Persons, Parsons, o Roberto Personio como se le llamaba en España, fue el más activo e influyente de los recusantes ingleses en el exilio, llegando a ser la figura más odiada por el gobierno de Inglaterra. Participó de todas las disputas tanto doctrinales como políticas de su tiempo, dejando casi siempre testimonio escrito de su postura, marcando la línea para muchos de los recusantes. Entre su proyectos para recuperar Inglaterra para el catolicismo se encontraba la fundación de seminarios para jóvenes ingleses que se plasmó en la construcción de varios de ellos como los de Douai

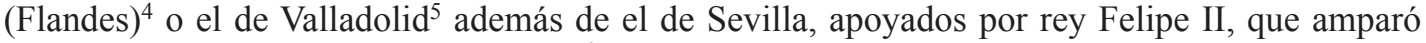
al jesuita en muchas de sus actividades ${ }^{6}$.

Aunque no era el rector del Colegio de San Gregorio, la influencia de Parsons se hacía notar tanto ideológica como espiritualmente. Un ejemplo de ello es lo recogido en un escrito del padre Francisco de Peralta, rector del colegio durante veintitrés años, donde se señala que tras la conversión al catolicismo de algunos presos ingleses de la Cárcel Real de Sevilla: "a ellos y a otros de la nacion se les han dado algunos libros espirituales que ha compuesto el Padre Personio con que mucho se han aprovechado"7.

La fuente principal a fines del siglo XVI y principios del XVII para conocer cómo fue la evangelización de Inglaterra y la relación del Papa Gregorio I con la Isla era la obra del venerable Beda, Historia Ecclesiastica Gentis Anglorum. A esta relación Beda le dedica desde el capítulo XXIII del libro primero hasta el capítulo I del segundo libro ${ }^{8}$. En este último capítulo se

2 Angulo, Diego, op. cit., p. 54.

3 YEPES, Diego de, Historia particular de la persecucion de Inglaterra y de los martirios mas insignes que en ella a auido, desde el año del Señor 1570. Madrid, 1599. pp. 764-767; OrTIZ DE ZúñIGA, Diego, Anales eclesiásticos y seculares de la muy noble y muy leal ciudad de Sevilla, metrópoli de Andalucía. Sevilla, 1988, vol. 4, pp. 152-153, vol. 5, p. 54; RoA, Martín de, Historia de la provincia de Andalucía de la Compañía de Jesús (1553-1602), Écija, 2005, pp. 315-317. Para la historia, los fondos del archivo y algunos documentos relacionados con el Colegio de San Gregorio, Murphy, Martin, St. Gregory's College, Seville, 1592-1767, Southampton, 1992.

4 Para la historia del Colegio inglés de Douai ver FABRE, F., "Le collège anglais de Douai: son histoire héroïque", Revue de littérature comparée, París, n. ${ }^{\circ} 10$ (1930) p. 201.

5 Para la historia del Colegio de San Albano de Valladolid ver Williams, Michael E., St. Alban's College, Valladolid: four centuries of English Catholic presence in Spain, Nueva York, 1986; BurRIEZA SÁNCHEZ, Javier, Una isla de Inglaterra en Castilla, Valladolid, 2000.

6 Para una breve biografía y bibliografía de Robert Parsons ver. O’NEILL, Charles E.-DomínGUEZ, Joaquín María (dir.) Diccionario histórico de la Compañía de Jesús: biográfico-temático, Madrid, 2001, vol. 3, pp. 3103-3104.

7 Murphy, Martin, op. cit., pp. 142-143.

8 La visión que ofrece Beda de la evangelización de Inglaterra y de la unidad del cristianismo en ella fue especialmente querida por los católicos tanto ingleses como españoles tras la ruptura de Enrique VIII, siendo esta obra muy citada y empleada como instrumento político. No es de extrañar que la primera edición en inglés moderno fuera realizada dentro del círculo de los recusantes en el exilio. Esta primera traducción se publicó en Amberes en 1565 siendo realizada por Thomas Stapleton (1535-158), profesor de teología y uno de los fundadores del colegio inglés de Douai. Sobre la repercusión de la obra del Venerable Beda en España en los siglos XVI y XVII y su uso político, cfr. Helmut HeIdenreich, "Beda Venerabilis in Spain”, MLN, Vol. 85, No. 2, Hispanic Issue. (Mar., 1970), pp. 120-137. Utilizamos la edición de la Historia Eclesiástica de Beda realizada por Stapleton por ser la más conocida en este período del que tratamos. 
recoge una antigua tradición en la que se narra cómo empezó el interés de San Gregorio, cuando aún era monje, por evangelizar Inglaterra. Estando en Roma pasó por un mercado entre cuyas mercancías vio unos jóvenes esclavos que llamaron su atención por su buena complexión, rostro agradable y bellos cabellos, interesándose por su procedencia y si en esas tierras eran paganos. El mercader le señaló que ese territorio aún era pagano y que los esclavos eran Anglos a lo que exclamó Gregorio, "bien, porque ellos tienen un rostro angélico, y como tales serán coherederos con los ángeles del cielo". La impresión que le causó aquellos jóvenes y el hecho que fueran todavía paganos impulsó al futuro Papa a intentar la evangelización de la isla de Britannia. Sin embargo, los habitantes de Roma no quisieron perder a una persona tan querida para ellos como Gregorio, logrando que permaneciera en la ciudad, siendo posteriormente nombrado diácono y llevado a la curia pontificia ${ }^{10}$.

Ya elegido Papa, Gregorio trazó un primer plan para la evangelización de la tierra de los Anglos. Envió una carta al presbítero Cándido, administrador del patrimonio papal al sur de la Galia, para que comprara esclavos anglos de entre diecisiete o dieciocho años, abundantes en los puertos de aquella zona. Su intención era que fueran enviados a algún monasterio en Roma para educarlos en la fe cristiana para más tarde destinarlos a la evangelización de Britania ${ }^{11}$.

Finalmente Gregorio optó por enviar un grupo de cuarenta monjes encabezados por Agustín, superior del convento benedictino de Roma. En el 596, tras algunos incidentes durante su viaje, Agustín y el resto de los monjes desembarcaron en la isla de Thanet perteneciente al reino de Kent, procedentes del reino de los francos. Desde allí enviaron un mensajero al rey Ethelbert (Etelberto, Edilberto o Edelberto), rey de Kent (o Cantio), que, tras rogarle en un primer momento que permanecieran en aquella isla, les permitió predicar y convertir cuantos pudieran además de ofrecerles alojamiento en Canterbury, la más importante de las ciudades de sus dominios. Las conversiones empezaron a ser numerosas, sufriendo un gran impulso tras el bautismo del propio rey Ethelbert y su corte el día de Pentecostés del año 597, tras lo cual los misioneros obtuvieron mayor libertad en sus labores de evangelización. Mientras, Agustín viajó a la ciudad de Arles donde, siguiendo las órdenes del papa Gregorio, fue creado arzobispo de la nación inglesa por Aetherius, regresando a Canterbury donde asentó su sede. Más tarde, el Papa, junto una carta en la que le daba las directrices de cómo debía ordenar nuevos obispos en Britannia, envió a Agustín un palio, para vestir sólo en la celebración de la Misa ${ }^{12}$.

Tiempo después Agustín, con la ayuda del rey Ethelbert, organizó una conferencia con los obispos Britanos ${ }^{13}$ en la que les pidió que se les unieran para evangelizar a los paganos además de rogarles que unificaran sus ritos tradicionales con los propios de la liturgia romana. Los obispos britanos rechazaron la autoridad de Agustín, lo que irritó a Ethelbert y especialmente a Ethelfrid, rey de Northumbria que se levantó en armas contra ellos provocando una gran matanza en la ciudad de Legions (Chester) ${ }^{14}$.

Ethelbert se convirtió en protector de la nueva religión llegando a construir la iglesia de San Pablo Apóstol en la ciudad de Londres ${ }^{15}$. El proceso de evangelización se puede resumir con las

\footnotetext{
${ }^{9}$ Esta respuesta de San Gregorio la tradición la recogerá como "Non Angli, sed Angeli" (no anglos, sino ángeles).

${ }^{10}$ BEDA, The history of the Church of Englande. Compiled by Venerable Bede, Englishman. Translated out of Latin in to English by Thomas Stapleton student in diuinite, Amberes, 1565. Lib. II. Cap. I. fols. 48-49; VorÁGINE, Santiago de la, La Leyenda Dorada, Madrid, 1982, vol. 1, pp. 186-187.

11 Diaconus, Joannes, Sancti Gregorii Magni Vita, Lib. II, cap. 46.

12 BeDA, op. cit., Lib. I. Caps. XXIII-XXXIV, Fols. 29-44.

${ }^{13}$ Los Britanos eran los primitivos habitantes de la isla. En esta época ocupaban la zona occidental empujados allí por las distintas invasiones germánicas que profesaban religiones paganas.

${ }^{14}$ Monmouth, Geoffrey de, Historia de los Reyes de Britania, Madrid, 1984, pp. 280-281.

15 Malmesbury, William de, "De gestis regum Anglorum", Rerum Anglicarum scriptores post Bedam praecipui, ex vetustissimis codicibus manuscriptis nunc primum in lucem editi, Londres, 1596, fol. 4.
} 
palabras escritas en el epitafio de la tumba de San Agustín de Canterbury ${ }^{16}$ : "Aquí yace el Señor Agustín, primer Arzobispo de Canterbury, siendo enviado aquí por el santo Gregorio, obispo de Roma, y apoyado por Dios en la obra de milagros, guió al Rey Ethelbert y a su nación desde la adoración de ídolos a la fe de Cristo, y teniendo fin los días de su oficio en paz, murió el día 26 de mayo, en el reino del mismo Rey" 17 .

Así, podemos identificar los personajes de la pintura de Juan de Roelas siguiendo la información ofrecida por estas fuentes. El centro de la composición la ocuparía el grupo formado por la figura sedente del Papa Gregorio Magno y a sus pies de rodillas, el santo rey Ethelbert. Esta no sería la única ocasión en que se plasmara la relación entre ambos personajes en el Colegio de San Gregorio. Procedente de Sevilla se conserva en el Colegio de San Albano de Valladolid, fundado por Parsons, una serie de ocho Santos Reyes de Inglaterra, atribuida a Francisco Pacheco, entre los que se cuenta San Edilberto (fig. 2). Al igual que todas las pinturas de la serie, una orla arquitectónica alberga la figura de medio cuerpo del santo, que lleva la corona sobre su cabeza y el cetro en su mano derecha. A su izquierda aparece una tiara papal con dos llaves entrecruzadas rematándose por una paloma de la que sale un leve rayo de luz, símbolos de San

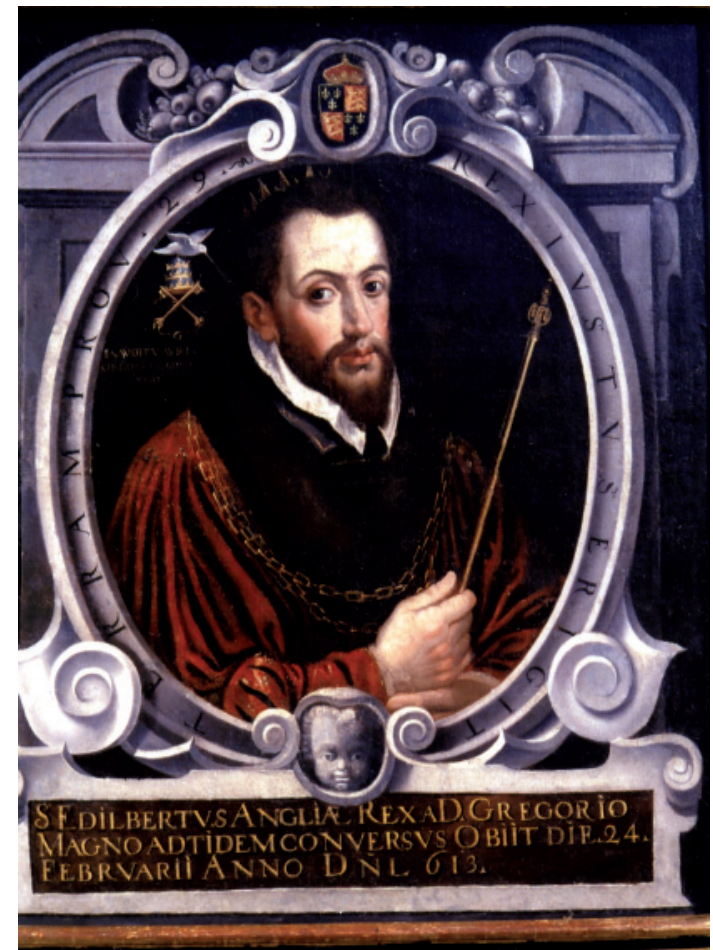

Fig. 2. Francisco Pacheco. San Edilberto. Colegio de San Albano. Valladolid.

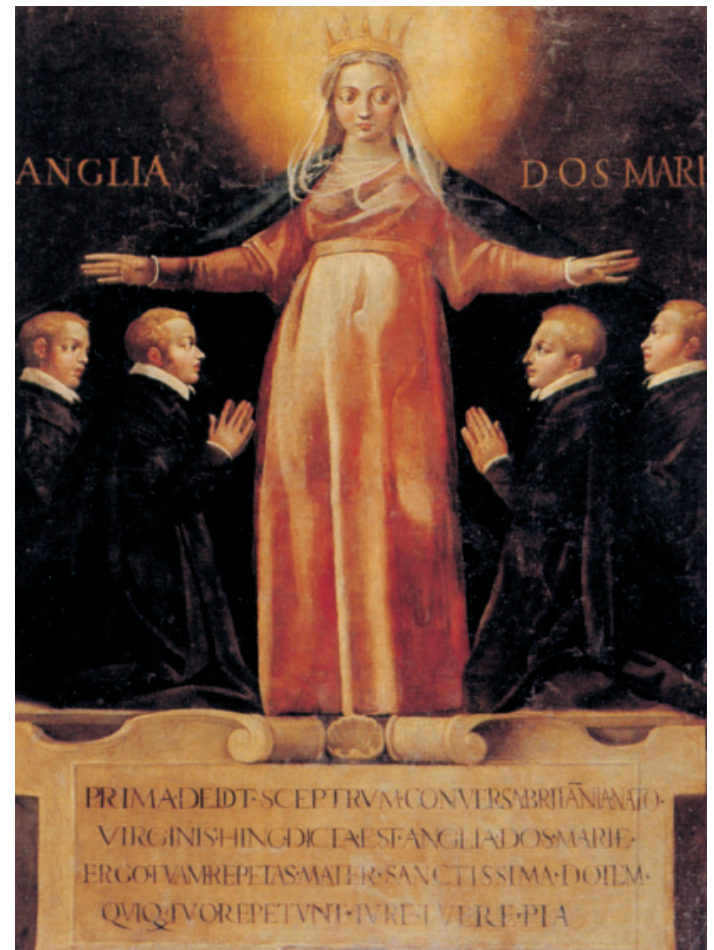

Fig. 3. Anónimo. Virgen de los Ingleses. C.1592. Real Academia de Medicina. Sevilla.

16 BeDA, op. cit. Lib. II. Caps. II-III, fols. 49-53.

17 BeDA, op. cit., Lib. II. Cap. II "Hic requiescit domnus Augustinus Doruuernensis archiepiscopus primus, qui olim huc a beato Gregorio Romanae urbis pontifice directus, et a Deo operatione miraculorum suffultus, Aedilbertcum regem ac gentem illius ab idolorum cultu ad Christi fidem perduxit, et conpletis in pace diebus officii sui, defunctus est VII Kalendas Iunias, eodem rege regnante". 
Gregorio Magno. Bajo estos símbolos aparece la frase: In auditu auri obedivit mihi: psm 1. (Al oírme me obedeció. Salmo 1). En el marco oval aparece grabado: Rex iustus erigit terram. Prov. 29. (Un rey justo hace prosperar el país. Proverbio 29); mientras que en la cartela inferior se lee: S. Edilbertus Angliae Rex ad Gregorio Magno ad fidem conversus. Obiit die 24 Februarii Anno Dñi 613. (San Edilberto rey de Inglaterra fue convertido a la fe por Gregorio Magno. Murió el día 24 de febrero de año del Señor 613$)^{18}$. Esta representación por tanto nos ayudaría a confirmar la identidad del santo rey arrodillado ante San Gregorio.

Flanqueando al Papa se situaría un grupo de cardenales pertenecientes a la Curia Romana, tal como los identificó Espinal. A la derecha, también de rodillas, el personaje revestido con hábito benedictino y palio sería San Agustín (de Canterbury o Inglaterra), que presenta al Papa dos escolares, seguramente de los comprados por Cándido para ser educados en Roma. En los dos personajes, vestidos con lujosas ropas según la moda inglesa de la primera mitad del XVI, de la esquina inferior izquierda se pueden reconocer como dos miembros de la corte de Kent. En la edición de Beda hecha por Stapleton en 1565 una xilografía muestra a Ethelbert rodeado por cortesanos, y al igual que en la pintura, todos visten según la moda de su época ${ }^{19}$.

Un acontecimiento como el aquí representado no se produjo nunca, siendo epistolar la única relación conocida entre San Gregorio y San Ethelbert ${ }^{20}$. Nos encontramos por tanto con una escena de carácter simbólico, más un sermón en imágenes que una representación realista de un hecho histórico, cuyo centro compositivo y del discurso iconográfico es el ofrecimiento de la corona y el cetro por parte del rey al Santo Papa. Como tal sermón que es este cuadro, lo representado es sólo el soporte para un discurso más complejo que no se relaciona únicamente con lo estrictamente literal de lo pintado.

El advenimiento de la Iglesia de Inglaterra o anglicana supuso la ruptura con la Santa Sede. Durante el reinado de Isabel I cualquier persona que quería ocupar un cargo eclesiástico, civil o de enseñanza debía prestar el Juramento de Supremacía en el que reconocía a la soberana como gobernadora suprema del país y como única autoridad en cuestiones eclesiásticas, negándosela a cualquier representante extranjero ${ }^{21}$. Aunque la muerte de la reina y la llegada al trono inglés en 1603 de Jacobo I, hijo de la católica María Estuardo, hizo albergar al principio esperanzas de tolerancia religiosa hacia los católicos, la realidad fue la contraria. La presión contra los católicos fue en aumento y tras la Conspiración de la Pólvora la situación empeoró aún más, particularmente para los jesuitas 22 .

En 1606 se aprueba una nueva ley en la que se incluía la obligación por parte los católicos de participar de la comunión anglicana al menos una vez al año, bajo pena de multa, y la prohibición de presentarse a Cortes o ejercitar la medicina si antes no realizaban un juramento de fidelidad al rey. Entre las cláusulas del Juramento de Fidelidad (Oath of allegiance) se incluía la de "aborrecer, detestar y abjurar como impía y herética la doctrina que atribuye al Pontífice Romano la facultad de excomulgar o deponer a los principes y que, sobre la base de dicha autoridad, legitima su asesinato por parte de sus súbditos "23. Así, se negaba tanto la autoridad temporal como espiritual del

\footnotetext{
18 VAldivieso, Enrique, "Una Serie de Santos Reyes de Inglaterra de Francisco Pacheco", Seminario de Estudios de Arte y Arqueología, Valladolid, 1994, pp. 463-468.

19 BEDA, op. cit., fol. 31.

${ }^{20}$ BeDA en su Historia Eclesiastica, lib. I, cap. XXXII, recoge una carta enviada por San Gregorio a Ethelbert. BEDA, op. cit., fols. 42-44.

21 Fraser, Antonia, La Conspiración de la Pólvora, Madrid, 1996, pp. 59-63.

22 Crosignani, Ginebra, De adeundis ecclesiis protestantium: Thomas Wright, Robert Parsons, S.J., e il dibattito sul conformismo occasionale nell'Inghilterra dell'etá moderna, Roma, 2004, pp. 201-208.

23 "In super iuro me animo abhorrere, detestari et abiurare, uti impiam et haereticam, damnabilem hanc doctrinam, et propositionem: Quòd Principes à Papa excomunicati, vel iure regali privati, possint regno vel vita ab ullo
} 
Papa, al declarar heréticas sus doctrinas, y como consecuencia obligaba a afirmar a los católicos que las enseñanzas trasmitidas durante siglos por la Iglesia Católica eran contrarias a la fe.

Inmediatamente el contenido fue objeto de acaloradas discusiones entre los que lo defendían, como el propio rey que publicó una Apología ${ }^{24}$ del mismo, y los que no podían admitir tal ataque, como Robert Parsons. Para Parsons, la negación de la autoridad temporal del Pontífice significaba menoscabar los principios fundamentales y de la pureza de la doctrina católica y por tanto este juramento no podía realizarse en los términos en que estaba formulado. Además el intento de los redactores de este juramento era negar que el Papa, como supremo pastor de la Iglesia Católica, tuviese la autoridad delegada por Cristo de proceder contra cualquier soberano temporal para conservar la religión cristiana ${ }^{25}$. Pero Parsons afirmaba que en estas cláusulas se entrelazaba el rechazo a la Autoridad Espiritual Papal al obligar al sujeto a renunciar a recurrir a su "Supremo Pastor" en cuestiones concernientes al gobierno de las almas. Así le recuerda directamente a Jacobo I, en la respuesta a su Apología, que "ningún Rey Cristiano Inglés ha rechazado por completo recurrir a Roma en cosas espirituales desde nuestro primer rey Ethelbert hasta Enrique VIII" y que incluso los soberanos más poderosos de la época le pedían consejo en cuestiones de conciencia sin que ello supusiera un menoscabo a su honor ${ }^{26}$.

La apelación a larga tradición católica de los reyes ingleses la encontramos también en los escritores españoles, especialmente jesuitas, que trataron la cuestión tanto durante la época isabelina como en el reinado de Jacobo I. Vemos cómo recuerdan una y otra vez el gran número de soberanos que alcanzaron la santidad incluso dando su vida y siendo martirizados defendiendo la fe católica, subrayando además cómo se sometieron a la autoridad papal ${ }^{27}$ y "desde aquel día [en que bautizaron a Ethelberto Rey de Cantio], hasta el año XXV del Reynado de Enrique VIII, que el de MDXXXIIII, despues del Nacimiento de N. Señor, por espacio de casi mil años no huvo en Inglaterra otra Fe, ni otra Religión, sino la Catolica Romana: y esto con tanta sujeción, obediencia, y fidelidad a la silla Apostolica,... $]^{28}$.

Y así lo afirma Juan de Peralta, rector de Colegio de los Ingleses de Sevilla en 1614, que justifica el título de Reino de Dios que le otorgaba a Inglaterra: "porque muchos de aquellos Reyes Sanctos lo fueron tanto, que fueron peregrinando a Roma, y ofrecían sus sceptros y coronas a la silla de San Pedro (...) y con la propia [grandisima devocion y humildad] reconocia, y davan la obediencia a los Summos Pontífces..."29.

Pero como buen sermón barroco, su significado no es único. Este ofrecimiento de los símbolos reales al Papa se relaciona también con la aparición entre nubes de la Virgen con el Niño. La devoción a la Virgen estaba muy arraigada entre los escolares del colegio de San Gregorio y

subditorum, vel alia persona quacunque privari”. JАСово I., Breuiculus duorum nuper in publicis comitijs Anglicanis actorum, Londres, 1606, fol. 4-5.

${ }^{24}$ JАсово, I., Triplici nodo, triplex cuneus. Or An apologie for the Oath of allegiance against the two breues of Pope Paulus Quintus, and the late letter of Cardinal Bellarmine to G. Blackvvel the Arch-priest, Londres, 1607.

${ }^{25}$ Crosignani, Ginebra, op. cit., pp. 215-235.

${ }^{26}$ PARSONS, Robert, The iudgment of a Catholicke Englishman, living in banishment for his religion (ST. Omer), 1608, pp. 10-11.

27 YePes, Diego de, op. cit., p. 3; SuÁrez, Francisco, Defensa de la fe católica y apostólica contra los errores del Anglicanismo, Madrid, 1970, vol. I, pp. 6-7.

${ }^{28}$ Ribadeneyra, Pedro de, Historia eclesiastica del scisma del Reyno de Inglaterra: en la qual se trata de el origen, y cosas mas notables, que han sucedido en aquel Reyno, tocantes à nuestra santa fè catolica..., Madrid, 1674, fol. 1-2.

29 Peralta, Francisco de, Copia de una carta que el padre Francisco de Peralta de la Compañia de Jesus, rector del colegio de los Ingleses de Sevilla, escrivio al padre Rodrigo de Cabredo... en que da cuenta de la dichosa muerte que tuvo en Londres la santa señora doña Luysa de Carvajal... y de las honras que se hizieron en la iglesia de San Gregorio Magno, apostol de Inglaterra en el colegio Ingles de Sevilla, en 11 de mayo de 1614, Sevilla, 1614, fol. 8. Peralta toma esta noticia de Polidoro Virgilio que en el libro IV de su Historiae Anglicae hace un relato de todos los reyes ingleses que fueron a Roma para ofrecer su cetro y su obediencia al Papa. 
los propios alumnos sentían "estar particularmente amparados bajo la protección de Nuestra Señora, la Reina del Cielo, contra la persecución de nuestra Reina de Inglaterra". Así, todos los días rezaban unas letanías a la Virgen ante una pintura de la misma que se encontraba en la entrada al primer patio del Colegio. Esta pintura (fig. 3), realizada en los primeros años del colegio y que se conserva en la actualidad en la Real Academia de Medicina de Sevilla ${ }^{30}$, presenta una Virgen de Misericordia con las manos extendidas en actitud de proteger a dos parejas de escolares de cabellos rubios que la flanquean y que rezan arrodillados ante ella. Se completa esta iconografía con unas palabras a ambos lados de la Virgen, "ANGLIA DOS MARIAE" (Inglaterra Dote de María), mientras que la zona inferior de la pintura la ocupa una cartela con cuatro versos, compuestos por Robert Parsons, que dan sentido al lema anterior: "Prima dedit sceptrum conversa Britannia nato / Virginis; hinc dicta est Anglia, dos Mariae. / Ergo tuam repetas mater sanctissima dotem, / Quique tuo repetunt iure, tuere pia" (Britannia convertida la primera entregó el cetro al hijo de la Virgen. Desde entonces se le llama Anglia dote de María. Por lo tanto, madre santísima, vuelve a recobrar tu dote, protege, piadosa, con tu justicia a los que van a recobrarla).

El propio Parsons desarrolla algo más el sentido de estos versos. Britannia, ahora llamada Inglaterra, fue el primer reino que se dio por entero a sí mismo y entregó su cetro real a Jesucristo, el hijo y esposo de Nuestra Señora. Así, según una opinión piadosa, los autores ingleses dijeron que Inglaterra era la dote de "Nuestra Señora". Por tanto, estos escolares de la pintura, en consideración que éste y todo santo honor, le fueron quitados, le suplican que recupere su antigua dote y que los asista para ir en su nombre y en el de su hijo para negociar este asunto, con la predicación y la enseñanza y ofreciendo su sangre para recobrarla ${ }^{31}$.

En consecuencia, podemos leer también este gesto del santo rey, el primero de Inglaterra tras el cual se recuperó la fe católica, según Parsons, como el momento de la entrega de su reino y de sus atributos reales a Cristo, a través de su representante en la tierra, el Papa, a lo que la propia Virgen y su hijo asisten. Se establece además un cierto paralelismo con la pintura antes descrita al mostrarse dos alumnos ingleses acompañados por San Agustín de Canterbury que, utilizando la oración y la enseñanza recuperó a la Inglaterra para el cristianismo.

Pero no es ésta la única relación que se establece entre la zona terrestre y la celestial. La Virgen porta una doble corona sobre sus sienes siendo una de ellas de flores mientras que el Niño Jesús se apoya sobre una bola del mundo rematada por una cruz. Esta bola del mundo, al igual que la corona, son atributos propios de los reyes mostrándose ambos como soberanos del "reino eterno en el cielo con el Dios vivo y verdadero", el mismo que Agustín prometió a Ethelbert que disfrutaría si seguía y obedecía su doctrina ${ }^{32}$. En este reino celestial la Virgen y el Niño se rodean de ángeles que portan guirnaldas y coronas de flores, llevando uno de ellos una palma, favores que se entregan a los mártires como premios a su defensa de la $\mathrm{Fe}^{33}$. El ofrecimiento de

\footnotetext{
${ }^{30}$ Murphy, Martin, op. cit., p. 29; AA.VV. La colección artística de la Real Academia de Medicina de Sevilla: 1700-2000, Sevilla, 2000, pp. 62-63.

${ }^{31}$ Parsons, Robert, Newes from Spayne and Holland..., Amberes, 1593, fols. 13-14; Francisco Peralta, al explicar el lema de “... DOS MARIAE”, expone los siguiente: "Llamase también dote de la Virgen; porque fue el primero Reyno de el mundo, que con su Rey se convirtio a la Religion Catolica, lo qual declaró en unos muy bueno versos que el padre Roberto Personio, que sea en gloria, que por ser tales, y de persona que tanto amó a V. Reverencia, los pondre aquí, como se ven en una ymagen muy devota, de nuestra Señora, que hicimos a los principios de este collegio, la qual tiene en lo alto esta letra. ANGLIA DOS MARIAE, y a los lados cada dos Alumnos de rodillas; que le suplican que cobre su dote; y que a ellos les ayude y socorra para ayudarselos a cobrar...". PERALTA, Francisco, op. cit., fol. 8.

32 BeDA, op. cit., Lib. I. Cap. XXV, fol. 31

33 En una representación gráfica, en varios niveles, de un sermón dado por uno de los alumnos de San Gregorio, en la que mostraba las "dos persecuciones por los dos Reyes Enriques de Inglaterra contra S. Tomás de Canterbury (Tomás Becket)" en su tercer nivel estaba pintado "bajo Enrique II, muchos ángeles con guirnaldas y coronas entre
} 
sangre que se hacía en la pintura de la Virgen comentada más arriba no era un simple recurso literario y los alumnos de San Gregorio eran conscientes de ello ${ }^{34}$. Los tratados y relaciones se encargaban de recordar las virtuosas muertes y martirios de los sacerdotes a lo que se le unía la concepción de los colegios jesuíticos como "fábrica de mártires", mostrándose deseosos los colegiales en ir a morir por su santa fe, siendo la envidia de sus compañeros por no poder "ser tan presto particioneros de sus suplicios, coronas y triunfos $" 35$.

Todas estas muertes eran consecuencia de las leyes aprobadas durante el reinado de Isabel I y ratificadas por Jacobo I después, por la que se ordenaba el ingreso en prisión inmediata de los sacerdotes sorprendidos en el acto de celebrar misa o en posesión de "ropa de misa" o de vasos sagrados, llegándose incluso a la pena de muerte si se les acusaba de traición. Se le sumaba también la detención inmediata de cualquier sacerdote católico procedente del exterior ${ }^{36}$. De hecho, en 1608 algunos alumnos del Colegio de San Gregorio ya habían sufrido estas leyes y habían sido ejecutados, convirtiéndose en mártires y alcanzado las coronas y la palma de la victoria del Reino Celestial que se mostraba en esta pintura y que estaba destinado también a los que siguieran sus pasos.

Pero volviendo a la zona terrenal, observamos cómo la escena se desarrolla en un exterior en el primer plano, ocupado en su mayoría por los personajes "ingleses", y un interior que llenan casi por completo San Gregorio y la curia vaticana, estableciéndose así una unión entre el territorio de Inglaterra y la Santa Sede. Se plasma así un recurso retórico que permite a Ethelbert entregar a San Gregorio en mano sus símbolos reales pero también ayuda a visualizar la unidad religiosa y doctrinal con Roma. Esta unidad se sustancia en el abrazo del Santo Papa al rey y en la interacción de algunos de los cardenales con los nobles y los colegiales y la presentación que de los mismos hace San Agustín a San Gregorio. Con esto no se pretendía exclusivamente recalcar de nuevo lo comentado más arriba sino también señalar que la $\mathrm{Fe}$ que predicó San Agustín era la misma que la de Roma. Esta necesidad se plantea debido a la afirmación por parte de algunos teólogos anglicanos en época de Isabel I e incluso por el propio Jacobo I que la religión predicada por San Agustín y, por tanto, la practicada en Inglaterra desde entonces no era la católica o al menos no era exactamente igual a la romana. De nuevo, entre los que respondieron a estos ataques se encontraba Robert Parsons que en su Teatrise of the Three Conversions of England ${ }^{37}$, intenta demostrar lo incorrecto de cada uno de los argumentos de estos teólogos y, cómo desde la llegada de San Agustín, enviado por San Gregorio, sin interrupción desde el reinado de San Ethelbert, la religión practicada en Inglaterra hasta el reinado de Enrique VII, seguía la ortodoxia romana.

Recapitulando, vemos cómo esta pintura, además de ser una respuesta a los ataques procedentes del anglicanismo, es un "sermón" destinado a los alumnos del Colegio de San Gregorio en la que se les recuerda que debían recuperar Inglaterra para la Cristiandad y para la Virgen María, tierra que había sido fiel al Papa antes que ningún otro reino y que para este fin debían

sus manos esperándolo para la Gloria y Salvación, por su penitencia y harta enmienda". PARsons, Robert, op. cit., 1593, fol. 12.

34 PARSOnS, Robert, op. cit., 1593, fols. 10-11; RoA, Martín de, op. cit., pp. 315-316.

35 Ribadeneyra, Pedro de, op. cit., p. 471.

36 Anónimo, Las leyes nueuamente hechas en el Parlamento de Inglaterra este año de M.DC.VI. contra los catolicos ingleses, que llaman recusantes. [S.1.: s.n., s.a.]; CRESSwELL, Joseph, Vando y Leyes del Rey Iacobo de Inglaterra contra la fe catolica con su respuesta y advertencias al letor [sic] para la aueriguacion e inteligencia deste caso, prouechosas para el mismo Rey y para todos, [S.l.: s.n., s.a.]. Fraser, Antonia, op. cit., p. 60.

37 En la primera parte de este tratado Parsons le dedica a este asunto desde el capítulo VIII al XI. En ellos replica fundamentalmente las ideas de John Foxe y de John Bale. PARsons, Robert, Teatrise of the Three Conversions of England, Londres, 1688, pp. 52-79. Casi las mismas ideas y las mismas respuestas son las que muestran el rey Jacobo I y el jesuita Francisco Suárez. Francisco SuÁREZ, op. cit., fols. 7-10. 
estar preparados para el sacrificio y el martirio que les permitiría alcanzar el verdadero reino que era el Celestial donde los únicos soberanos son Cristo y su Madre.

GonZalo José Martínez del Valle 